\title{
Senior High School Students References in Choosing Orthodontic Treatment Provider: A Study in Marelan Subdistrict 2018
}

\author{
$\underline{\text { Feni Firdanigrum }}{ }^{1}$, Kintoko Rochadi ${ }^{2}$, Ameta Primasari ${ }^{3}$ \\ ${ }^{1}$ Faculty of Public Health, Universitas Sumatera Utara, Indonesia \\ 2Departement of Health Promotion, Faculty of Public Health, Universitas Sumatera Utara, Indonesia \\ 3Departement of Oral Biology, Faculty of Dentistry, Universitas Sumatera Utara, Indonesia \\ Email: peni_drg@yahoo.co.id
}

\begin{abstract}
:
Initially the use of orthodontic appliance (braces) was intended to tidy up the teeth that had an irregular shape. The phenomenon of braces is increasingly prevalent among teenagers because in addition to health reasons then developed into a reason to support the appearance and eventually become a self-identity for adolescents. Finally, there are more victims of dental artisans who report disruption of oral health due to the installation of braces on dental artisans. Because the installation is not in accordance with the medical standard. The purpose of this study was to determine how senior high school student choose orthodontic treatment provider. To achieve these objectives, research was conducted using independent variables, namely knowledge, cost, distance, family support. The subjects of this study were 105 senior high school students. The subjects were taken using non-probability sampling and purposive sampling techniques. The data analysis method used is multiple linear regression test by taking into account the simultaneous test, classic assumption and partial test, correlation test determinant. The results of this study indicate that the variable cost $(p=0,0001)$, distance $(p=0,014)$ and consumer knowledge $(p=0,014)$ significantly influence the dependent variable (consumer decision) while the family support variable $(p=1,000)$ has no effect. Different from family ( $p=$ $1,000>0.05)$ support that has no relationship with consumer decision-making to choose orthodontic treatment provider, service costs $(p=0,0001<0,05)$, the distance traveled by respondents $(p=0.014<0.05)$ and knowledge of respondents $(p=0.014<0.05)$ have relationship with consumer decision making to choose orthodontic treatment provider both in Public and Private High Schools, and Public and Private Vocational Schools in Marelan Subdistrict, respectively.
\end{abstract}

Keywords:

references; choosing; orthodontic; treatment provider

\section{Introduction}

Nowadays many people are interested in orthodontic treatment but most are only for lifestyles. This is because there is still a lack of public awareness that the function of orthodontic treatment is to tidy up irregular tooth structures and facial deformities due to the inconsistency of the jaw connection so that it can affect the mastication, digestion, and articulation systems1. In general, orthodontic treatment aims to improve the lives of patients by overcoming psychosocial difficulties related to the face and teeth.

Orthodontic treatment performed by operators who are not competent, poor and improper maintenance procedures will cause adverse effects. These will effects include tooth decay, poor oral ears. The equipment used is inappropriate and causes discomfort and irritation to gingiva, lips and cheeks3. Orthodontic dentists and general dentist are the right 
operators who have competence in orthodontic treatment.

The trend of orthodontic treatment is a modern lifestyle that can affect a person's behavior. Currently the adolescent's behavior in the habits of orthodontic care has led to irrational consumption because teenagers take action where the initial goal of doing orthodontic treatment is to tidy up teeth but now only aim for lifestyle or fashion so that it can have a negative effect on orthodontic treatment. This study aimed to determine how senior high school student choose orthodontic treatment provider.

\section{Research Methods}

This study used a descriptive observational approach with a cross-sectional design. This research was carried out in several public and private high school, public and private vocational school in Marelan Sub-District, Medan, and the population was all teenagers who wore tooth braces. With a purposive sampling technique, the number of samples was 105 people including the following inclusion criteria aged 15-18 years, using tooth braces or fixed orthodontic, sample of braces at dentist and personnel other dentists, and willing to be a research sample by signing the informed consent.

Table 1. Measurement method

\begin{tabular}{llllll}
\hline Variables & $\begin{array}{l}\text { Total } \\
\text { Question }\end{array}$ & Value & Total & Category & Scale \\
\hline Family support & 7 & 1 & $\geq 4$ & Good & Ordinal \\
& & 0 & $<4$ & Bad & \\
Level of & 9 & 1 & $0-3$ & Low & Interval \\
knowledge & & 0 & $4-6$ & Medium & \\
Distance & 3 & 1 & $7-9$ & High & \\
& & 0 & $\leq 1$ & Affordable & Ordinal \\
Cost & 5 & $1=0,1,2$ & $>5$ & Unreacheable & \\
& & $2=1,2,3,4$ & $\leq 5$ & low & Ordinal \\
& & $3=1,2$ & & & \\
& & & & \\
& & $5=0,1$ & & & \\
& & & & & \\
\end{tabular}

Collecting data was by direct observation and using questionnaire that were asked directly by the researcher. Univariate analysis was carried out to showed the frequency distribution of gender, parental work, duration of use stirrup and type of stirrup used. Bivariate analysis with the chi-square test using a 95\% confidence level to determine the relationship between the independent variable and dependent variable in choosing stirrup usage facilities among teenagers. If the $\mathrm{p}$ value less than $0,05(\mathrm{p}<0,05)$ then the statistic is related.

\section{Discussion}

\subsection{Result}

This research obtained information from the sample that people's perception, in this case the factors that influence the selection of orthodontic treatment in non-professional personnel. Obtained information that the most of respondents were come from SMA Budi Agung that is as much as 33,3\% dan and the least were come from SMK Bina Taruna (table 2). 
Britain International of Humanties and Social Sciences (BIoHS) Journal

ISSN: 2685-3868(Online), 2685-1989(Print)

Vol. 2, No. 1, February 2020, Page: 264-270

Table 2. Frequency Distribution of Respondent's schools ( $\mathrm{n}=105)$

\begin{tabular}{llr}
\hline School & Frequency & \% \\
\hline SMA 16 & 30 & 28,6 \\
SMK Binasatria & 34 & 32,4 \\
SMK Bina Taruna & 6 & 5,7 \\
SMA Budi Agung & 35 & 33,3 \\
\hline Total & 105 & 100.0 \\
\hline
\end{tabular}

Showed that the number of respondents who used braces most were women that as much as $93,3 \%$ and $6,7 \%$ were men, and most rerpondents have $41,9 \%$ of parents who work as private employees, then as civil servants as much as $21 \%$, entrepreneur as much as $13,3 \%$, as factory worker as much as $9,5 \%$, as laborer as much as $9 \%$, and the least as force as much as $5,7 \%$.Most of the respondents $(64,8 \%)$ have used braces for $1-2$ years and the least were respondents with the use of stirrups for more than 3 years as much as 13,3\%. Most of the respondents use braces as much as $62,9 \%$ compared to those who use it for treatment $(37,1 \%)$ (Table 3).

Table 3. Characteristics of Respondents

\begin{tabular}{lcc}
\hline Characteristics of Respondents & Frequency & $\mathbf{\%}$ \\
\hline Gender & & \\
Female & 98 & 93.3 \\
Male & 7 & 6.7 \\
Parental work & 22 & \\
$\quad$ Civil servant & 14 & 21,0 \\
Entrepreneur & 6 & 13,3 \\
Force & 10 & 5,7 \\
Factory workers & 44 & 9,5 \\
Private workers & 9 & 41,9 \\
Laborer & & 8,6 \\
Duration of braces usage & 23 & \\
Recently & 68 & 21,9 \\
1-2 years & 14 & 64,8 \\
$\quad$ 3 years & & 13,3 \\
Braces type & 66 & 62,9 \\
Fashion & 39 & 37,1 \\
Treatment & & \\
\hline
\end{tabular}

From the table 4.3, it is known that the high cost of installing braces makes them choose to go to non-professional personnel, which is as much as 58 respondents $(100 \%)$. While from 47 respondents who stated that the orthodontic treatment provider price was quite cheap, there were 31 respondents $(66,0 \%)$ who still chose the dental artisan, while those who chose the dentists were only $34 \%$. There was a relationship between the level cost and the reason for choosing orthodontic treatment provider $(p=0,0001)$.

Showed that 55 respondents $(93,2 \%)$ stated that the distance closer to the nonprofessional's orthodontic treatment provider than those close to the dentists $(6,8 \%)$. As many as 34 respondents $(73,9 \%)$ still chose to install braces at the non-professional despite the distance travel and those chose to the dentist were $26,1 \%$. There was a relationship between distance traveled by the reason of choosing orthodontic treatment provider $(p=0,014)$. 
Based on the table 4 we found that the majority of respondents had medium knowledge level, as many as $88,3 \%$ chose to service dental by non-professional personnel and only $11,7 \%$ chose the dentists. From 26 respondents with high level of knowledge, only 2 respondents $(7,7 \%)$ chose the dentists and the rest chose to the non-professional personnel as many as $92,3 \%$.From the group of respondents with a low level of knowledge, most of them $(63,2 \%)$ chose to install braces to the non-professional personnel and only 7 respondents chose to the dentists. There was a relationship between the level of knowledge with the reason of choosing orthodontic treatment provider $(\mathrm{p}=0,014)$. (Table 4$)$.

Table 4. Bivariate Analysis

\begin{tabular}{|c|c|c|c|c|c|}
\hline \multirow{3}{*}{ Independent variables } & \multicolumn{4}{|c|}{ Choosing braces use facilities } & \multirow{3}{*}{$\mathbf{P}$ value } \\
\hline & \multicolumn{2}{|c|}{ Non-Professionals } & \multicolumn{2}{|c|}{ Dentists } & \\
\hline & $\mathbf{n}$ & $\%$ & $\mathbf{n}$ & $\%$ & \\
\hline \multicolumn{6}{|l|}{ Family support } \\
\hline $\mathrm{Bad}$ & 21 & 87,5 & 3 & 12,516, & \multirow{2}{*}{1,000} \\
\hline Good & 8 & 84,0 & 13 & 0 & \\
\hline \multicolumn{6}{|l|}{ Cost } \\
\hline Expensive & 58 & 100 & 0 & 0 & \multirow[t]{2}{*}{0,001} \\
\hline Cheap & 3 & 66,0 & 16 & 34,0 & \\
\hline \multicolumn{6}{|l|}{ Distance } \\
\hline Unreachable & 55 & 93,2 & 4 & 6,8 & \multirow[t]{2}{*}{0,014} \\
\hline Affordable & 34 & 73,9 & 12 & 26,1 & \\
\hline \multicolumn{6}{|l|}{ Knowledge level } \\
\hline Low & 12 & 63,2 & 7 & 36,8 & \multirow{3}{*}{0,014} \\
\hline Medium & 53 & 88,3 & 7 & 11,7 & \\
\hline High & 24 & 92,3 & 2 & 7,7 & \\
\hline
\end{tabular}

\subsection{Discussion}

The growing trend of braces causes the number of places to appear braces installation at low cost without paying attention to the effects caused after installation. Recently orthodontic devices are much favored by adolescents. According to the American Dental Association (1999), there are $81,5 \%$ of adolescent patients who use orthodontic devices9. In adolescence there are physical and mental social changes. This causes many teenagers use braces only for fashion without regard to the negative effects that can be caused if installed in any non-professional personnel practice. From the results of this study, it was found that there were still many adolescents who performed orthodontic treatment at dental artisan or nonprofessional personnel and only aimed at fashion

\section{a. Family Support}

From the chi-square test results $(p=1,000)$ that there is no relationship of family support for respondent decision making to choose braces usage facilities in some high school and vocational schools in Marelan subdistrict. The demand for orthodontic treatments is mainly driven by appearance problems and other psychosocial factors. In this context, braces users have a specific goal to be achieved related to their identity, namely the status of being fashionable person. That is what has become the mainstream of teenagers today. Descartes see the body as a machine. The body is only an object that must follow the cultural mainstream and continue to be modified according to the demands of the times13. Aesthetic often plays an important role in the patient's decision to seek orthodontic treatment, even needs in other medical cases. It is generally understood that dental aesthetics add physical attractiveness, physical health, and beauty. Therefore, many teenagers who also installed 
braces were not for reasons of dental abnormalities / care but for fashion, so they did not feel it was important family support, so most high school and vocational students in the Marelan subdistrict area made braces installation based on their own will without any encouragement from the family.

\section{b. Cost}

Orthodontic treatments performed at orthodontic dentists and general dentists do require substantial costs. This is due to the materials and tools used during the patient's care. In addition, dentist fees are naturally more expensive than dental artisan because the time and costs incurred for taking education to obtain competency as a dentist are not few and other things with dental artisan who skills are sometimes only handed down from generation to generation or skills educations that should be used in a laboratory and not to deal directly with the community.

The amount of the cost of installing braces at the dentist makes many teenagers prefer to install braces at the dental artisans. Data on the socio-economic conditions of the community (parental work) in Marelan Sub-District, Medan, shows that most of them are private employees, civil servants, entrepreneur, laborer, factory workers, and the majority of them who chose braces installing at dental artisans were parental work as private and factory workers, also laborers. Therefore, it is understandable if people are looking for cheaper health services. The results of this study illustrate that respondents who view affordable service costs will certainly choose to utilize braces installation to the service area. This can be seen as many as 58 of the 105 respondents who stated that the costs of affordable services turned out to make them prefer dental artisans to dentists. From the results of the chi-square tests, there is a relationship between the cost of treatment to respondent decision making to choose braces usage facilities $(\mathrm{p}=0,0001)$.

This is in line with McGrath and Bedi' research which states that economic status is the most important predictor for someone in making decision to take care. Socio-economic conditions of a family can be measured based on family income from the results of existing work14. A study conducted by Sarnizia in 2008 in Medan found that 92,5\% stated that relatively cheaper costs for dental artisans were the main reason for the use of dental artisan services rather than dentists.

\section{c. Distance}

From the results of the chi-square tests, there is a relationship between the distance traveled by respondents to consumer decision making to choose braces usage facilities in several high school and vocational schools in Marelan sub-district.

This is in line with Kaunang's research (2014) conducted in the community in the village of Treman in the Kauditan sub-district about respondents' perception of needs, found an average score assessment of 395. The assessment was included in the good category, where alternative answers agreed to very strongly agree on the results of the study in the village Treman showing that the respondents made dentures on dental artisans. Dental artisans are the main choice for the people in Treman village as dental service providers because the dental artisans live in there. In addition, there is no dentist who serves the community in the village Treman and the nearest health center does not serve the manufacture of dentures, so the community prefers to go to dental artisans due to the distance and practical of dental artisans practices16. 
In obtaining public health services, the people generally look for a closer one because it is considered that apart from the economics point of view, such as costs, the community also takes into account the time and energy that is exhausted and in order to obtain these services, the community prefers cheap17.

The results of the study are in line with the theory which states that the geographical location of the distance an affect the participation of mothers to make visits to health services. Long distances and the amount of costs will be considered by the community in using health services. According to research, long distances and long periods of time will become obstacles for the community in seeking health services. In general, mothers will seek the nearest health service.

\section{d. Knowledge}

Knowledge is a very important domain for the formation of one's actions. Knowledge is needed as support in fostering confidence and attitudes and behavior every day, so that it can be said that knowledge is a fact that supports ones action18. From the above understanding can be explained that motivation is an impulse that moves an individual to do better things. Variables such as knowledge, education, family background and cultural environment can change the interest or thrust possessed by a group of needs in certain individuals.

From the results of the chi-square test obtained a value $(p=0.014),(p<0.05)$ which means that there is a relationship between respondents' knowledge and consumer decisionmaking to choose orthodontic treatment provider in several senior high schools and vocational schools, in Marelan sub-district. The results of this study are in line with the theory which stage about health in general can be interpreted as a tool to improve themselves in terms of health. Knowledge involves conservative and progressive elements (change). Conservative elements of knowledge give effect or as a result of previous generations to the next generation. While the progressive element will have a positive impact on change as a result of the existence of knowledge. Knowledge about the health of a person is expected to bring a better behavior changes. According to the assumptions of researchers, through education, someone can increase maturity to think so that they can make better decisions in behaving. The level of education is believed influencing someone to get better health services.

\section{Conclusion}

From the result and discussion above, the conclusion can be drawn as foloows:

1. There is no relationship of family support $(\mathrm{p}=1,000>0.05)$ on consumer decisionmaking to choose orthodontic treatment provider in both Public and Private High Schools, and Public and Private Vocational Schools in Marelan Subdistrict.

2. There is a relationship between service costs $(p=0,0001<0,05)$ on consumer decision making to choose orthodotic treatment provider in both Public and Private High Schools, and Public and Private Vocational Schools in Marelan Subdistrict.

3. There is a relationship between the distance traveled by respondents $(p=0.014<0.05)$ on consumer decision making to choose orthodotic treatment provider both in Public and Private High Schools, and Public and Private Vocational Schools in Marelan Subdistrict.

4. There is a relationship between knowledge of respondents $(p=0.014<0.05)$ on consumer decision making to choose orthodontic treatment provider both in Public and Private High Schools, and Public and Private Vocational Schools in Marelan Subdistrict. 


\section{References}

Cecep, H. K., Rosihan, A., \& Diana W. (2017). Relationship between the level of knowledge of respondents with the selection of operators other than dentists in terms of the dangers of installing orthodontic devices. Dentino Jural Dentistry, 2(2).

Dewi, O. (2007). Analysis of the relationship of malocclusion with quality of life in adolescents of high school in the city of Medan 2007 (Thesis, Faculty of Dentistry, University of North Sumatra). Available from http://repository.usu.ac.id/ bitstream/handle/123456789/669/08E00229.pdf;jsessionid=D941689CB47E37830F 9C15CF04350B01?sequence $=1$

Ekowati, R. (2002). Specific strategies in accelerating village maternity hospital development in java. Jakarta : JKPKPBBK/Badan Litbang Depkes dan Kesejahteraan Sosial. Available from http:// digilip.litbang.depkes.go.id.

Hensu, C., Anindita, P.S., \& Mariati, N.W. (2013). Orthodontic treatment needs based on index of orthodontic treatment need di SMP Khatolik Theodorus Kotamobagu. J eGigi, 1, 99-104.

Herwanda, Rafinus, \& Lindawati. (2017). Knowledge of adolescents aged 15-17 in the city of Banda Aceh for the side effects of using fixed orthodontic devices. Jurnal of Syiah Kuala Dentistry Society, 1(1), 79-81.

Kaunang, W. (2014). Community perception of making dentures by dental workers in Treman Village. Kauditan District.

Mantiri, S., Vonny, N., \& Anindita, S. (2013). Oral hygiene status and dental caries status of students using fixed orthodontic devices. J e- Gigi, 1, 1-7

McGrath, C., \& Bedi, R. (2002). Severe tooth loss among UK adults - who goes for oral rehabilitation? J Oral Rehabil, 29, 240-4.

Meutuah, S. (2013). Relationship between characteristics of dentures and utilization of dental artisan services in the city of Medan 2008 (Thesis, Faculty of Dentistry, University of North Sumatera). Available from http://repository.usu.ac.id/bitstream/123456789/14734/1/090E00980.pdf

Mieke, S. (2006). The role of extra celluler matrix during orthodontic treatment. Folia Media Indonesiana, (42), 1-7

Norman, N., Sarah, A., Ulfat, B., \& Atta, U. (2011). Effect of orthodontic treatment on periodontal health. Pakistan Oral \& Dent Journal, 31(1), 111-114

Notoatmodjo S. 2007. Health promotion and behavioral sciences. Jakarta: PT Rineka Cipta.

P.Robbins, Stephen. 2006. Organizational behavior. Jakarta: PT.Indeks Kelompok Gramedia

Pramono, M. (2007). Culture of body objectivity: Philosophy of Cartesian Dualism. Jurnal Alafkar Fakultas Ushuludin IAIN Sunan Ampel, 19(1).

Sarwono, S. 2012. Health sociology. Yogyakarta: Gadjah Mada University Press

Sulandjari, H. (2008). Orthodontic textbook I KGO I. Yogyakarta : Faculty of Dentistry, Gadjah Mada University.

Sulmayeti. (2015). Perilaku konsumsi pemakaian kawat gigi non medis. Jurnal FISIP Universitas Riau, 2(1).

Wahid, M., Henry, S. S., Lintang D.S., \& M. Sakundarnoa. (2017). Differences in dental plaque scores, Saliva $\mathrm{pH}$, and oral hygiene status in users and non-users of fixed orthodontic devices. Journal of Public Health, 5(3).

WHO. (2013). Adolescent Health. Accessed https://www.who.int/maternal_child_ adolescent/adolescence/en/ 